\title{
NUANCES DA RELAÇÃO ENTRE CULTURA E POLÍTICA NO CONTEXTO DA DITADURA MILITAR NO BRASIL
}

\author{
Cristiane Rodrigues Soares \\ Fabiana de Paula Guerra \\ Leudjane Michelle Viegas Diniz
}

(Mestrandas do Programa de Pós-graduação em História Social da Universidade Federal de Uberlândia).

Resumo: Resultado de reflexões promovidas pela disciplina Estudos Alternativos em História e Cultura, do mestrado em História Social, da Universidade Federal de Uberlândia, este artigo visa discutir a relação entre cultura e política entre as décadas de 1960 e 1980 - período de ditadura militar no Brasil. Consideramos, na análise aqui proposta, as formas de recepção (de discursos e produtos culturais), ressaltando algumas formas de resistências nesse contexto.

Palavras-chave: cultura, política, ditadura militar, recepção, engajamento, artistas/intelectuais.

Abstract: As a result of reflections promoted by the subject-matter Alternative Studies in History and Culture, given as part of the Social History' Master's degree course at the Universidade Federal de Uberlândia, this article aims to discuss the relationship between culture and politics which took place between the 1960s and the 1980s - a period when Brazil was under the military dictatorship. We consider in this analysis the ways of reception (of speeches and cultural products), highlighting some ways of resistance in such context.

Keywords: culture, politics, military dictatorship, reception, involvement, artists/intellectuals

A proposta de analisar a relação existente entre cultura e política, em tempos de ditadura, parte do suposto de que essa discussão não se limita apenas a um dos diversos âmbitos que a história - enquanto área do conhecimento - comporta. Sendo assim, consideramos que a noção de política não se restringe às instituições oficiais (como o Estado, a Igreja, os sindicatos) e as pessoas vinculadas a elas, relacionando-se também com aspectos culturais, ou seja, a forma como nos inserimos na sociedade, dando respostas variadas a questões que nos afetam, direta ou indiretamente. 
Nessa perspectiva, percebemos que a política está presente em nosso cotidiano, na maneira como nos posicionamos em nossas práticas sociais e culturais, buscando meios diversificados de representação e de expressão de nossos anseios e necessidades. Por isso, vale atentar para a relação existente entre cultura e política, considerando que esta se expressa, de forma diferenciada, em variados contextos históricos.

As considerações do autor Michel de Certeau caminham nesse sentido, ao discordar das concepções correntes, na medida em que defende o cotidiano como o lugar marcado pela passividade e reprodução, percebendo esse espaço de forma politizada. Ao analisar as práticas cotidianas, através das quais os usuários/consumidores criam meios de se relacionarem com uma cultura que não produzem, o autor percebe a cultura como um campo de disputas, afirmando que

(...) a cultura articula conflitos e volta e meia legitima, desloca ou controla a razão do mais forte. Ela se desenvolve no elemento de tensões, e muitas vezes de violências, a quem fornece equilíbrios simbólicos, contratos de compatibilidade e compromissos mais ou menos temporários. As táticas do consumo, engenhosidades do fraco para tirar partido do forte, vão desembocar então em uma politização das práticas cotidianas (CERTEAU, 1996, p. 45).

Com base nesses pressupostos, Certeau nos coloca a questão da apropriação, levando em conta a criação e a invenção, ou seja, a capacidade de conceber algo novo a partir do que já existe. Pensando na produção cultural, atenta para o fato de que não recebemos passivamente os produtos (e também os discursos) que nos são impostos pois, ao nos apropriarmos deles, damos-lhes novos significados e sentidos, de acordo com nossos interesses, nossas necessidades e nossas possibilidades. É neste ponto que reside a "arte de fazer" ou a potencialidade criadora dos consumidores.

Outro aspecto pertinente, para o qual Certeau chama a atenção, é a necessidade de pensarmos nos consumidores também como produtores. Dessa forma, percebemos que eles não são passivos ou simples receptáculos do que lhes é passado, visto que criam suas próprias interpretações, de acordo com suas vivências e necessidades, multiplicando, assim, nossas possibilidades de análise.

A presença e a circulação de uma representação (ensinada como código da promoção sócioeconômica por pregadores, por educadores ou por vulgarizadores) não indicam de modo algum o que ela é para seus usuários. É ainda necessário analisar a sua manipulação pelos praticantes que não a fabricam. Só então é que se pode apreciar a diferença ou a semelhança entre a produção secunda que se esconde nos processos de utilização. (CERTEAU, 1996, p. 40). 
No caso dos leitores, compreender que não são indiferentes - e que podem (re)significar aquilo que lêem, construindo os seus discursos e contradiscursos, de acordo com suas necessidades e seus interesses - é importante para a analise da recepção de determinados textos literários, jornalísticos, dentre outros, não os vendo como uma "via de mão única". Muitas vezes, o autor tem uma intenção específica, ao escrever um texto, o que não determina que a leitura deste, por aqueles que lhe tiverem acesso, caminhará de acordo com a intenção original. Isso significa que o sentido inicial de um texto pode ser alterado ao ser apropriado por outras pessoas, com perspectivas de análise diferenciadas. E essa observação não se limita, apenas texto, mas se estende a outros produtos culturais.

As questões apontadas por Certeau são válidas para observarmos como se dá a recepção de uma obra artística ou de um determinado produto cultural, considerando o processo de interação entre produtor e consumidor e apontando para o fato de que, o ato de consumir e o de produzir, encontram-se imbricados. Entender como uma obra foi produzida e de que modo foi lida ou está sendo lida pela sociedade que a recebe, constitui um desafio para o pesquisador.

No que concerne ao cinema, este é um aspecto fundamental a ser considerado, haja vista que não recebemos, acriticamente, as mensagens contidas num filme. Isso pelo fato de que os interesses de quem produziu as imagens diferem das interpretações que o público fará delas. Vale ponderar que as pessoas podem utilizar as representações presentes nas imagens, manipulando-as e dando-lhes sentidos que se afastam do intuito inicial do produtor, para criar outras representações, a partir de suas experiências.

Um outro autor que também se preocupa com a questão da recepção do público a um produto cultural, no caso específico da literatura, é Benoît Denis. Ele discorre sobre os vínculos entre literatura e engajamento, observando que, ao se produzir uma obra, não é possível estabelecer, a priori, qual será o público alcançado. Ainda que o autor tenha a intenção de direcionar seu trabalho para um tipo específico de público, não consegue controlar ou saber, de antemão, quais os indivíduos que terão contato com a sua produção, ou mesmo como eles irão apropriar-se de seu conteúdo, dando-lhe interpretações próprias.

Denis deixa claro, na apresentação de seu texto (DENIS, 2002), que devemos atentar para a historicidade do termo engajamento como um conceito datado e situado no século XX, no período entre-guerras (conhecido como apogeu sartriano), com forte 
ressonância no pós-Segunda Guerra Mundial. Essa consideração não nos impede de utilizar este conceito para pensar outros contextos históricos, mas nos alerta para observarmos as especificidades próprias de cada momento, evitando anacronismos.

Com Sartre, a questão do engajamento literário ganha amplas dimensões, mas é válido lembrar que, antes dele, outros autores já utilizavam este termo com outras abordagens. A literatura engajada estaria voltada, fundamentalmente, para uma preocupação com o social, na qual o autor transpareceria, claramente, seu olhar e sua visão de mundo, em suas obras, não sendo, pois, a literatura um objeto neutro.

(...) O escritor engajado coloca em jogo bem mais do que a sua reputação literária; ele arisca a si mesmo integralmente na escritura, fazendo aparecer aí a sua visão do mundo e as escolhas que dirigem a sua ação. (...) engajar-se consiste assim em colocar a sua pessoa na linha de frente da obra literária, isso significa também que o escritor assume a hipótese de que ele possa ser julgado a partir de suas obras (DENIS, 2002, p. 46).

Na perspectiva sartriana, o escritor engajado é aquele voltado para os problemas do seu tempo; desse modo, escreve sobre o momento presente, recusando uma escrita literária destinada ao leitor de elite. Para tanto, faz um "apelo ao profano" para atingir um número maior de leitores, o que faz ser secundária a preocupação com a estética da obra. Para Sartre, o conteúdo e a viabilidade da sua mensagem, para alcançar os leitores, são o aspecto primordial. Nesse sentido, afirma que o escritor pertence ao mundo, na medida em que está inserido nas questões de sua época, atuando no sentido de alterá-las. Dessa forma, o escritor (e sua obra) estaria a serviço de um projeto de transformação social.

Ao falar do posicionamento do escritor, engajado com a função de escrever para determinado público (e isso significava também escrever no lugar dele), Sartre estabelece que a relação entre o escritor e o público é bastante desigual: "o primeiro permanece sempre o senhor do jogo e se concebe como aquele que revela ao segundo o que ele é e o que ele espera" (DENIS, 2002, p. 62-3). Sendo assim, Sartre atribui ao público certa passividade, na medida em que é visto apenas como receptor dos discursos que lhes são impostos, ou seja, se o escritor utilizar uma linguagem acessível - e isso pode corresponder a um rebaixamento, no sentido estético da obra - será compreendido, levando o outro (receptor) a acatar suas idéias.

Podemos perceber que este posicionamento de Sartre está embutido da idéia de que o escritor deveria instruir os menos esclarecidos, mostrando-lhes a melhor maneira de 
se posicionarem frente a determinados problemas. Essa é uma visão, bastante deturpada, do outro, pois não considera que este possua capacidade suficiente para construir seus próprios valores e idéias acerca do mundo.

Alguns historiadores, como Marc Bloch (2002), também afirmam a importância do engajamento e da militância; consideram que o historiador tem, em primeiro lugar, um compromisso social com a humanidade e não, especificamente, com seus pares. Dessa forma, seu espaço de atuação/interação não deve restringir-se às academias, mas estar voltado para a sociedade na qual está inserido. Com base nestes apontamentos, Bloch nos coloca a questão do sentido da história, afirmando que este reside, justamente, na sua capacidade de oferecer condições para compreendermos o momento e o meio em que nos situamos.

Importa salientar que Denis explicita, em seu texto, as diferenciações entre engajamento e militância. O primeiro termo estaria relacionado com escolha, com o ato de se doar, engajar-se, colocando seu ofício a serviço da humanidade. Pressupõe, assim, do engajado, um compromisso ético com valores; não só com questões especificamente políticas. Como já foi dito, o conceito remete a um sentido de urgência, de dar respostas a questões hodiernas. Já o segundo termo relaciona-se com a atuação direcionada a questões políticas, no seu sentido tradicional. Ou seja: a militância está vinculada a instituições oficiais, como por exemplo, os partidos políticos.

As discussões levantadas por esse autor servem para pensarmos, com as devidas ressalvas, o contexto da ditadura militar no Brasil (1964-1985), percebendo que, militância e engajamento, caminhavam lado a lado, nesse período. No caso das esquerdas armadas, os militantes (que se encontravam vinculados a uma organização ou partido político) deveriam ser, também, engajados, capazes de dispor da própria vida a favor de um projeto coletivo de transformação social. Assim nos fala Denis, sobre o sentido do engajamento, apresentado no texto acima referido:

No sentido figurado, engajar-se é desde então tomar uma certa direção, fazer a escolha de se integrar numa empreitada, de se colocar numa situação determinada, e de aceitar os constrangimentos e as responsabilidades contidas na escolha. Por conseguinte, e sempre de modo figurado, engajar-se consiste em praticar uma ação, voluntária e efetiva, que manifesta e materializa a escolha efetuada conscientemente. (DENIS, 2002, p. 32).

Por meio desta noção de engajamento, podemos analisar a postura de militantes 
e guerrilheiros que se colocaram a serviço de uma causa político-social, norteando suas ações, de acordo com suas convicções ideológicas e assumindo os riscos de suas escolhas. O sentido de urgência, de agir com o intuito de oferecer uma resposta imediata, ao momento atual, está presente em Sartre, caracterizando, também, a militância das esquerdas armadas no pós-1964.

É preciso considerar, na análise aqui proposta, que o período pré-64 caracterizase como um momento de estreita vinculação entre cultura e política, atrelada a constantes debates em prol da transformação da sociedade brasileira. Corroborando essa afirmação, de que a década de 1960 representa um período de grande efervescência cultural, Walnice Galvão comenta:

O panorama do início da década de 60 mostra a maior animação: no quadro do governo populista de Jango Goulart, era grande a efervescência. Tudo parecia aberto à mudança, o novo estava no ar, o ímpeto vital dos jovens iluminava de futuro o momento e com ele se confundia. A pequena faixa social integrada pelos intelectuais e artistas jovens de esquerda, e um ou outro menos jovem, mas não temeroso da crescente radicalização, devotava-se à tarefa urgente de levar a cultura ao povo, arriscando os equívocos em que isso possa implicar. (GALVÃO, 1994, p. 185-86).

Toda essa movimentação, segundo a autora, desembocou numa criação cultural extremamente vivaz. Vale frisar que é nesse contexto que ocorre um grande impulso no campo do teatro (com destaque para o Arena e o Oficina), no cinema, na literatura, na música, contestando amplas questões em voga no momento.

Buscava-se, através de atividades culturais, deselitizar a cultura e levá-la até o povo (como se este não a tivesse). E essas atividades eram, na visão de Galvão, consideradas como um dever político de participação e interação social. O início dessa década é abordado pela autora como um período de freqüentes contestações por parte pessoas que se empenhavam na construção de novas formas de convivência e de cultura, mas que, no entanto, foram paralisadas com o golpe militar de 1964. Paralisadas porque, na sua concepção, o golpe fizera com que toda aquela produção artístico-cultural, politizada, fosse desaparecendo, pelo fato de seus produtores não terem mais possibilidades de realizar manifestações, principalmente após o AI- $5^{1}$. Nesse sentido, considera o regime militar como totalmente repressor e os movimentos culturais pós-1968, como despolitizados. ${ }^{1}$ O Ato Institucional $n^{\circ} 5$ entrou em vigor em 13 de dezembro de 1968 , perdurando até 31 de dezembro de
1978. Esse ato era mais abrangente e repressor que os anteriores, centralizando o poder de decisões na 
Podemos observar, nesse contexto, um forte recrudescimento do regime, a instauração da censura, da repressão e da violência contra a sociedade civil, com grande ímpeto, na tentativa de silenciar as vozes contrárias ao regime, com golpes de cassetete, torturas, exílio ou até mesmo com o fim da própria vida daqueles que eram considerados subversivos. No âmbito cultural, percebemos o fortalecimento dos meios de comunicação de massa, como no caso da indústria televisiva, com destaque para a Rede Globo, que recebeu apoio governamental, compactuando, de certo modo, com o regime até então instalado.

Porém, diferentemente da tese defendida por autores como Walnice Galvão de que após o AI-5 "a oposição estava liquidada" (2001, p. 191) - a resistência ao regime se fez presente no movimento estudantil, na música e no teatro engajados, na guerrilha rural, dentre outros, demonstrando um compromisso social e uma crítica à situação vigente, de forma que, tais espaços tornaram-se redutos de oposição ao regime. Desse modo, tornase fundamental valorizar as brechas encontradas pelos mais diversos segmentos populares para demonstrar que era possível resistir e que nem todos compactuavam ou "abaixavam suas cabeças" para as atrocidades cometidas durante a ditadura militar.

Refletindo sobre esse período - mais especificamente sobre as décadas de 1960 e 1970 - Marcelo Ridenti utiliza os conceitos de "estruturas de sentimento", de Raymond Williams, e de "romantismo", de Löwy e Sayre, para analisar as produções artísticas do período em questão. Podemos dizer que este autor apresenta inovações ao pensar a realidade brasileira a partir de conceitos oriundos da História Cultural.

A dificuldade de se utilizar o termo estruturas de sentimento está presente no trabalho de Ridenti (2005), que nos fala sobre a complexidade do conceito, porém sem desconsiderar a sua validade na análise dos valores, das idéias, das representações e dos significados que eram compartilhados por amplos setores de artistas e intelectuais, no contexto por ele analisado. O autor relaciona este conceito com a forma como respondemos às mudanças sociais que ocorrem em nossa volta, expressando essas respostas em nossas práticas cotidianas.

Ridenti utiliza o termo, articulando-o ao conceito de romantismo, para nos apresentar sua concepção de "estrutura de sentimento romântico-revolucionário", que se 
expressava nos anos 60, em várias instâncias, como no Cinema Novo, no Teatro de Arena, nos Centros Populares de Cultura (CPC), ressaltando que essa estrutura de sentimento não surgiu da luta contra a ditadura, haja vista que já vinha sendo constituída anteriormente, num processo que apontava para mudanças, em diversos setores da sociedade, numa perspectiva revolucionária.

Buscava-se o homem novo, com certa idealização do homem do povo, do campo, desvinculado do apego às coisas materiais e afastado da perspectiva do capitalismo/consumismo. Importa salientar que, nesse momento, caminhava-se em busca de novos referenciais, sendo que, artistas e intelectuais, também tentavam estabelecer um diálogo produtivo com o público (o povo) para o qual sua produção se destinava.

Vários desses artistas e intelectuais, membros de certos partidos e movimentos de esquerda, enfatizavam a construção desse novo homem, cujo modelo estava no passado, ou seja, nas raízes rurais (do interior), homem que, supostamente ainda não teria sido "contaminado" pela modernidade urbana capitalista. Sendo assim, buscava-se no passado uma cultura popular autêntica para construção de uma nova nação que, ao mesmo tempo, fosse moderna e desalienada. Como aponta Ridenti, recolocava-se o problema da identidade nacional e política do povo brasileiro, ao mesmo tempo em que se propunha a ruptura com o subdesenvolvimento.

No período anterior ao golpe, havia uma utopia de transformação, não só da realidade social, mas também do próprio homem, em sociedade, voltado para questões coletivas, próprias de um projeto político revolucionário. Na contramão das análises de Galvão, Ridenti afirma que, mesmo após a derrota, caracterizada primeiro pelo golpe, em 1964, e posteriormente pela intensificação exacerbada da repressão em 1968, com o AI-5, alguns artistas não se calaram, utilizando uma nova linguagem — indireta e metafórica — para continuarem expressando-se. Contudo, nos chama a atenção para as mudanças que ocorreram nesse contexto: “Após as derrotas de 1964 e de 1968, a busca romântica da identidade nacional do homem brasileiro permaneceria, porém, mudavam as características desse romantismo, que foi deixando de ser revolucionário para encontrar um lugar na nova ordem" (RIDENTI, 2005, p. 100).

Assim, o autor coloca que, os conceitos que utiliza para desenvolver seus estudos, não são cristalizados, visto que sofrem constantes alterações, de acordo com o 
contexto em que estão inseridos. Daí, a importância de atentarmos para a historicidade dos conceitos que utilizamos no desenvolvimento de nossas pesquisas.

No que se refere a estruturas de sentimento, o autor aponta para o fato de que, como a ditadura conseguiu desestruturar os propósitos daqueles que eram contrários ao regime, fazendo com que os mesmos buscassem outras formas de (re)inserção social ${ }^{2}$, a estrutura de sentimento romântico-revolucionária entrou em declínio, dando lugar a uma outra estrutura: a da individualidade pós-moderna.

Com o fim da utopia revolucionária e com a busca por um lugar de atuação (e até mesmo de sobrevivência na nova ordem, ou seja, numa sociedade onde o capitalismo impera de forma expressiva), percebemos o declínio do intelectual, que antes se voltava para questões públicas/coletivas e que passa a ter, após a ditadura, um campo restrito de atuação, preocupando-se com questões particulares, como, por exemplo, a sua carreira: "A institucionalização de intelectuais e artistas neutralizaria a liberdade de que em teoria dispõe, de modo que, um eventual sonho com a revolução conviveria com o investimento na profissão, no qual prevaleceria a realidade cotidiana da burocratização e do emprego" (RIDENTI, 2005, p. 105). Neste contexto, percebemos como os locais de debates críticos se tornam restritos, limitando-se, muitas vezes, ao espaço das universidades.

A partir das considerações de Ridenti, podemos pensar em como se dá o diálogo com diferentes temporalidades, ainda que próximas, já que é a partir de questões postas pelo presente que voltamos nosso olhar e nossa atenção para o passado. Ao analisar produções que remetem ao período do regime militar no Brasil, coloca-se a questão de como lidar com este passado recente, que muitas vezes é considerado como indesejado e doloroso. E essa análise perpassa a relação entre memória, história, esquecimento e ressentimento.

Daniel Aarão Reis é um dos autores que discorrem sobre as reconstruções da memória, percebendo que ela é sempre seletiva, podendo ora revelar, ora ocultar ou alterar os fatos aos quais se refere. Ele está preocupado em compreender como foi construída uma

\footnotetext{
${ }^{2}$ Muitos artistas e intelectuais, tendo seus projetos vencidos e percebendo a impossibilidade de se produzir de forma "engajada" num contexto de fechamento político-cultural, encontraram espaço para suas produções no âmbito da indústria cultural, estruturada no Brasil no período da ditadura. Marcos Napolitano discute o fato de estes artistas e intelectuais não serem simplesmente cooptados por essa indústria, na medida em que tinham como proposta alcançar o público/as massas e os meios da indústria cultural lhes davam essa possibilidade (ver NAPOLITANO, 2004).
} 
memória sobre a ditadura, ou seja, como os acontecimentos vivenciados nesse período foram posteriormente interpretados por diversos grupos sociais.

É importante destacar que o campo de construção da memória é permeado por disputas nas quais “(...) os derrotados de ontem, na luta aberta, podem ser os vitoriosos de amanhã, na memória coletiva" (REIS, 2004, p. 30). No que diz respeito às esquerdas, Aarão Reis observa que elas foram derrotadas nos embates sociais, mas que, após a ditadura, surgiram vitoriosas nas batalhas da memória. Não obstante, essa memória começou a se constituir a partir do momento em que a ditadura foi perdendo sua popularidade, afastandose cada vez mais da democracia que, no discurso (e somente nele!), propunha-se a restabelecer.

Acreditamos que, a maneira como o autor interpreta as ações dos sujeitos envolvidos, tanto na legitimação quanto no combate à ditadura, auxilia no rompimento com uma visão corrente e estereotipada dos militantes como vítimas/heróis e dos militares como os algozes/"gorilas da repressão", atentando para outros aspectos ainda pouco explorados, como as bases sociais do regime militar. Afinal de contas, esse regime político não foi imposto arbitrariamente sem qualquer tipo de apoio por parte de setores da sociedade civil.

Não há como negar que um dos fatores que possibilitaram, à ditadura, perdurar por tantos anos foi o respaldo social que possuía. É verdade que, muitos que ajudaram a legitimar esse regime, num outro contexto, auxiliaram no processo de redemocratização. Mas isso não nos impede de reconhecer que a ditadura não foi totalmente imposta, pois se estabeleceu com o apoio de alguns grupos. Atentar para estes fatores pode nos ajudar (dentre outros aspectos) a romper com uma perspectiva voltada para o esquecimento, ao enfrentar dificuldades, em recordar um período histórico tão recente. Nesse sentido, Daniel Reis afirma:

Sempre quando os povos transitam de uma fase para a outra da história, e quando a seguinte rejeita taxativamente a anterior, há problemas de memória, resolvidos por reconstruções mais ou menos elaboradas, quando não pelo puro e simples esquecimento. A sociedade brasileira, depois que aderiu aos valores e às instituições democráticas, enfrenta grandes dificuldades em compreender como participou, num passado ainda muito recente, da construção de uma ditadura, que definiu a tortura como política de Estado. (REIS, 2004, p.49).

A questão do esquecimento encontra respaldo no processo de anistia, que propôs como condição para sua existência a conciliação entre as partes envolvidas. Ao beneficiar 
torturados e torturadores, impediu a apuração dos crimes cometidos, num discurso que apontava para o progresso do futuro, e não para as mazelas do passado. Sendo assim, definiu o esquecimento dos fatos como uma forma de superá-los. Vale ressaltar que os descontentes com este "pacto" foram considerados — e são ainda hoje, em certa medida — rancorosos, revanchistas e ressentidos.

Contudo, mesmo com esses impasses e/ou empecilhos, foi possível construir uma memória sobre o período, ainda que fragmentada, no que se refere aos testemunhos e às documentações ${ }^{3}$. Irene Cardoso (2001) analisa tais questões ao discorrer sobre a temática memória/esquecimento, com o propósito de elaborar modos de aproximação dos acontecimentos de 1968. A autora nos diz que esse ano foi marcado por uma convulsão de sentimentos contraditórios, nos quais havia imagens de alegria e tristeza, de vida e morte. $\mathrm{O}$ início do ano é caracterizado (para os militantes) por aspectos positivos, no sentido de intervenção social, ou seja, havia a sensação de se estar participando das decisões, dos rumos tomados pela sociedade. Já no final (desse mesmo ano), essa positividade transforma-se num pesadelo em que a "alegria de viver" é substituída pela "sorte de viver" - principalmente após o AI-5, observa-se o aumento da repressão e do uso deliberado da tortura como política de Estado.

Para dar conta de compreender os significados desses sentimentos diversos, a autora propõe uma abordagem interdisciplinar, afirmando que "A presença de imagens de vida e morte faz de 68 uma situação limite, política e existencial, e traz para a interpretação questões que só poderão ser elaboradas de um modo que ultrapasse o enfoque estritamente disciplinar" (CARDOSO, 2001, p.137-38).

Dessa forma, o enfoque proposto nos chama a atenção para não analisarmos um fato isoladamente, mas, ao contrário, percebê-lo como parte de um processo e recebendo influências de outros acontecimentos. Com base nessas considerações, a autora analisa movimentações de vários setores sociais, em 1968, destacando que são frutos de demandas por reivindicações que já estavam em curso desde o início da década de 60 e que foram

\footnotetext{
${ }^{3}$ Essa observação é válida para os acontecimentos relativos à contestação da ditadura, em especial para o episódio da guerrilha do Araguaia - movimento político-militar ocorrido na região sul do Pará, entre os anos de 1972 e 1974, organizado pelo Partido Comunista do Brasil. No que concerne a esse fato, há poucas informações, ausência de documentações e imensa relutância das Forças Armadas em assumir sua participação no conflito, assim como a existência de arquivos que comprovem as táticas utilizadas no combate à guerrilha. Podemos perceber que o silêncio em torno desse fato é tão grande, que ainda hoje não foram encontrados os corpos da maioria dos guerrilheiros que morreram na luta.
} 
influenciadas por acontecimentos internacionais, como a revolução cubana, a guerra do Vietnã, a morte de Che Guevara, na Bolívia, o "maio de 68”, na França, dentre outros.

A questão do esquecimento e da memória é pensada por Cardoso, a partir de três registros considerados como fundamentais, sendo eles:

O de um passado que não se torna passado - a dificuldade de sua simbolização ou representação; o da interdição mesma do passado - a anistia proposta a partir da restrição da exumação do passado e a prática de normalização da sociedade e da política que daí decorre; o do esquecimento como método mesmo de sobrevivência social e individual nos "tempos da violência." (CARDOSO, 2001, p. 249).

Vale destacar que as pessoas que vivenciaram situações-limite - medo, dor, culpa, perda etc. - nas fronteiras tênues, entre vida e morte, apresentam dificuldades em criar/estabelecer representações acessíveis à memória ${ }^{4}$, utilizando, na maioria dos casos, o esquecimento (e, às vezes, o ressentimento), como forma de cicatrização de lembranças dolorosas, com as quais não se consegue conviver satisfatoriamente.

No que diz respeito às dificuldades de se criarem representações desse passado (que remete à ditadura), podemos dizer que estamos avançando, haja vista a considerável produção cultural que tem sido elaborada atualmente sobre o período, como arquivos, livros, filmes, dentre outras. Nesse rol, Araguaya: a conspiração do silêncio ${ }^{5}$ é uma produção cinematográfica que nos serve de exemplo, na medida em que se encaixa nessa

\footnotetext{
${ }^{4}$ Idelber Avelar expressa essa questão como "crise do testemunho", apontando para a dificuldade de se traduzir, em linguagem (numa narração), experiências extremas de terror e/ou violência pelas quais se passou (Cf. AVELAR, 2003).

5 FICHA TÉCNICA: Araguaya: a conspiração do silêncio. Brasília, 105 min. Direção: Ronaldo Duque. Produção: Ronaldo Duque e Marcio Curi. Produtores associados: Sâmia Gabriel, Daniel Gomez e Patrick Siaretta. Argumento e roteiro: Ronaldo Duque, Guilherme Reis e Paula Simas. Figurino: Maria Carmem Souza. Música original: Rênio Quintas. Som: Chico Bororo. Fotografia: Luís Abramo e Jacques Cheuiche. Direção de produção: Luiz Antônio Gerace (Chacra). Direção de arte: Pedro Daldegan e Eurico Rocha. Direção executiva: Marcio Curi. Montagem: André Cardoso. Organização de elenco: Guilherme Reis. Intérpretes: Stephane Brodt (Padre Chico), Fernanda Maiorano (Tininha), Northon Nascimento (Osvaldão), Françoise Forton (Dora), Danton Mello (Carlos), Narcisa Leão (Lúcia), Rosanne Holland (Alice), Rômulo Augusto (Flávio), William Ferreira (Juca), Cacá Amaral (Mário), Pablo Peixoto (Geraldo), Cláudio Jaborandi (Cabo Abdon), Humberto Pedrancini (General Mamede), Fernando Alves Pinto (Tenente Álvaro), Adriano Barroso (Anselmo). Produtora: Fábrica de Fantasias Luminosas, 2004.

SINOPSE: O filme busca reconstituir o episódio ocorrido na região sul do Pará entre os anos de 1972 e 1974, conhecido como guerrilha do Araguaia. Para isso, retoma o ano de 1968, trazendo como protagonista um padre que dá assistência aos moradores do local e se torna amigo dos guerrilheiros, sem saber ao certo quem realmente eram. É através desta personagem — que vivencia o drama da miséria e do abandono a que aquela população é relegada, presenciando a inominável violência com a qual as Forças Armadas ocupam a região, dando início ao conflito - que a história é contada no desenrolar da trama.
} 
perspectiva de análise, ao buscar romper com um silêncio imposto após o processo de anistia e trazendo para o debate elementos para constituição de uma memória sobre a guerrilha, que contribua para que tal acontecimento, de luta por uma série de direitos, não se perca em meio ao esquecimento que já é característico de nossa sociedade.

\section{REFERÊNCIAS BIBLIOGRÁFICAS}

AVELAR, Idelber. A escritura do luto e a promessa de restituição. In: Alegorias da derrota: a ficção pós-ditatorial e o trabalho do luto na América Latina. Belo Horizonte: Editora da UFMG, 2003, p. 235-259.

BLOCH, Marc. Apologia da história ou ofício de historiador. Rio de Janeiro: Jorge Zahar Editor, 2002.

CARDOSO, Irene. Os acontecimentos de 1968: nota para uma interpretação e memória de 1968: terror e interdição do passado. In: Para uma crítica do presente. São Paulo: Editora 34, 2001, p. 133-61.

CERTEAU, Michel de. A invenção do cotidiano: artes de fazer. Petrópolis: Vozes, 1996.

DENIS, Benoît. Literatura e engajamento: de Pascal a Sartre. Bauru: Edusc, 2002.

GALVÃO, Walnice Nogueira. As falas, os silêncios (literatura e imediação: 1964-1988) In: SCHWARTZ, Jorge; SOSNOWSKI, Saul (Org.). Brasil: o trânsito da memória. São Paulo: Editora da Universidade de São Paulo, 1994, p. 185-95.

NAPOLITANO, Marcos. Engenheiros das almas ou vendedores de utopia? A inserção do artista - intelectual engajado no Brasil dos anos 70. In: FICO, Carlos. et al. 1964-2004: 40 anos do golpe - ditadura militar e resistência no Brasil. Rio de Janeiro: 7 Letras, 2004, p. 309-320.

REIS, Daniel Aarão. Ditadura e sociedade: as reconstruções da memória. In: REIS, Daniel Aarão; RIDENTI, Marcelo; MOTTA, Rodrigo Patto Sá (Org.). O golpe e a ditadura militar: quarenta anos depois (1964-2004). Bauru: Edusc, p. 29-52.

RIDENTI, Marcelo. Artistas e intelectuais no Brasil pós-1960. Tempo Social, v. 17, n. 1, São Paulo, USP, 2005, p. 81-110. 